\title{
Contralateral extradural hematoma following decompressive craniectomy for acute subdural hematoma (the value of intracranial pressure monitoring): a case report
}

Lucas Crociati Meguins ${ }^{1,4^{*}}$, Gustavo Botelho Sampaio ${ }^{1}$, Eduardo Cintra Abib , Rodrigo Antônio Rocha da Cruz Adry ${ }^{1}$, Richam Faissal El Hossain Ellakkis ${ }^{1}$, Filipe Webb Josephson Ribeiro ${ }^{1}$, Ângelo Luiz Maset ${ }^{2}$ and Dionei Freitas de Morais ${ }^{3}$

\begin{abstract}
Introduction: Decompressive surgery for acute subdural hematoma leading to contralateral extradural hematoma is an uncommon event with only few cases previously reported in the English medical literature.

Case presentation: The present study describes the case of a 39-year-old White Brazilian man who had a motorcycle accident; he underwent decompressive craniectomy for the treatment of acute subdural hematoma and evolved contralateral extradural hematoma following surgery.

Conclusion: The present case highlights the importance of close monitoring of the intracranial pressure of severe traumatic brain injury, even after decompressive procedures, because of the possible development of contralateral extradural hematoma.
\end{abstract}

Keywords: Acute subdural hematoma, Decompressive surgery, Extradural hematoma

\section{Introduction}

Traumatic brain injury (TBI) represents an important life-threatening disease. In 2009, the US Centers for Disease Control and Prevention estimated that at least 2.4 million emergency department visits, hospitalizations, or deaths were related to a TBI, either alone or in combination with other injuries [1]. Posttraumatic intracranial mass lesions are commonly seen after severe TBI and are usually involved in the pathophysiology of intracranial hypertension. They may vary from extra-axial mass lesions (acute subdural hematomas, [ASDHs], and extradural hematomas, [EDHs]) to intraparenchymal mass lesions (contusions and intracerebral hematomas) [2-5]. However, EDH following decompressive surgery for ASDH is an uncommon

\footnotetext{
* Correspondence: lucascrociati@hotmail.com

${ }^{1}$ Faculdade de Medicina de São José do Rio Preto (FAMERP), Residente do Serviço de Neurocirurgia, Hospital de Base, São Paulo, Brazil

${ }^{4}$ Rua Pedro Palotta, 101/31B. Jardim Maracanã, 15092205 São José do Rio Preto, São Paulo, Brazil

Full list of author information is available at the end of the article
}

situation with only few cases previously reported in the English medical literature [6-10].

The present report describes the case of a Brazilian man who evolved EDH following decompressive surgery for ASDH. We review similar cases previously published.

\section{Case presentation}

A 39-year-old White Brazilian man was admitted to our Emergency Department after a motorcycle accident on a highway. Although he was hemodynamically stable, a neurological assessment revealed a Glasgow Coma Scale (GCS) of six points and right eye mydriasis. No clotting dysfunction was detected by laboratory test. Computed tomography $(\mathrm{CT})$ of his brain revealed right side ASDH, hemispheric edema and midline shift of $15.7 \mathrm{~mm}$ with compression of his right lateral ventricle (Figure 1). He was immediately transferred to the Operating Room and a right decompressive craniectomy was performed. He was kept under sedation and his intracranial pressure (ICP) was continuously monitored in the intensive care 


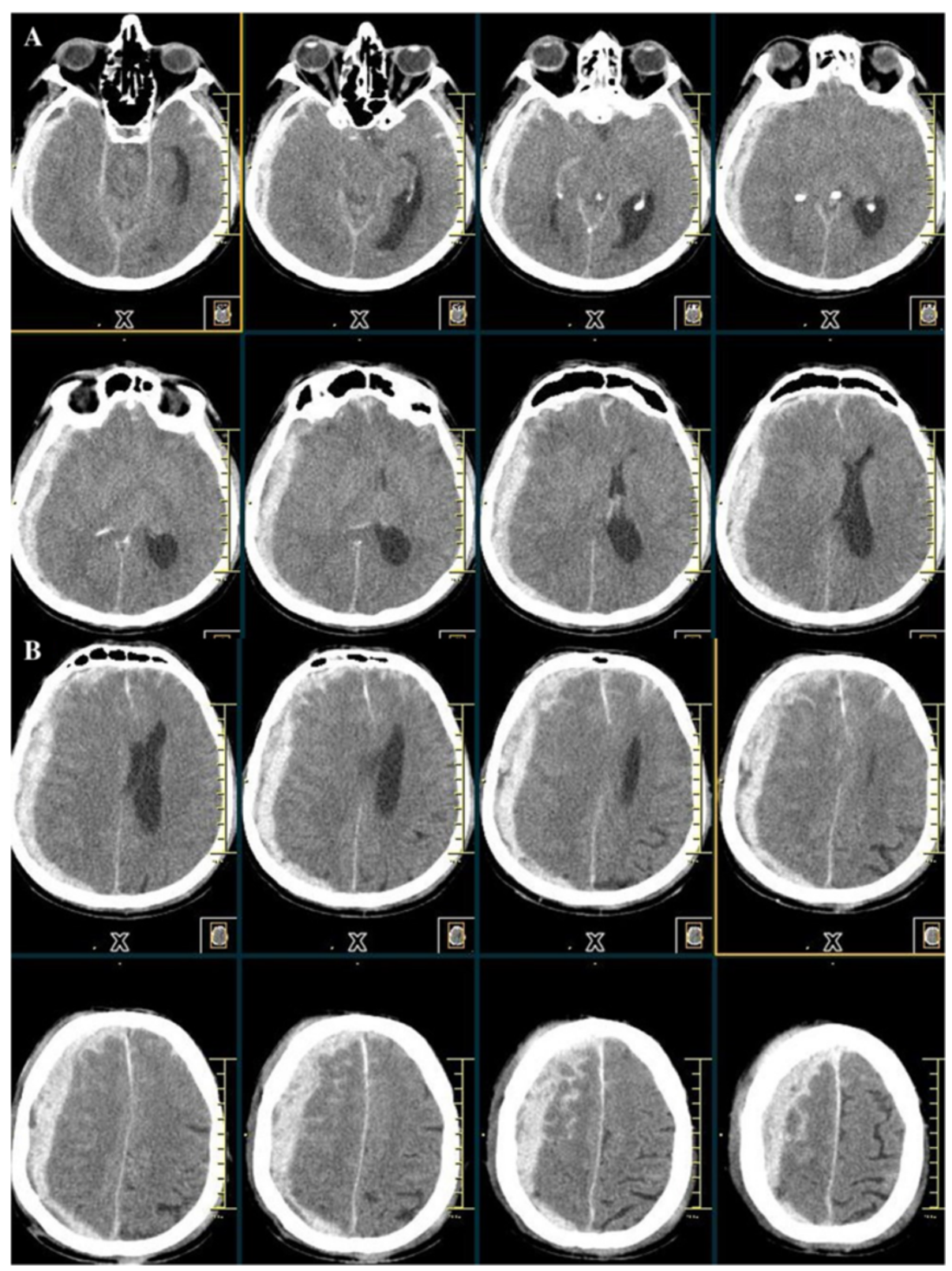

Figure 1 (A/B): Admission computed tomography showing right acute subdural hematoma.

unit. On the first postoperative day, he started to present elevated ICP refractory to hyperventilation and osmotic therapy. A new CT was then obtained and showed a large contralateral EDH (Figure 2) and frontal hemorrhage associated with catheter insertion. He was taken again to the Operating Room and surgical evacuation of the hematoma was performed. A brain CT following the second operation, revealed no residual EDH (Figure 3). He evolved hemodynamically unstable within the first 48 hours and no neurological improvement was observed after weaning sedation. He died on the ninth postoperative day.

\section{Discussion}

Posttraumatic intracranial mass lesions are commonly seen after severe TBI and are usually involved in the pathophysiology of intracranial hypertension. ASDH is frequently associated with other intracranial abnormalities, and only $30 \%$ to $40 \%$ of all ASDHs requiring surgery are isolated lesions $[11,12]$. The most frequently associated intracranial lesions are contusions and intracerebral hematomas, associated EDHs are noted in 6\% to $14 \%$ of patients $[12,13]$. However, EDH following decompressive surgery for ASDH is an extremely uncommon 


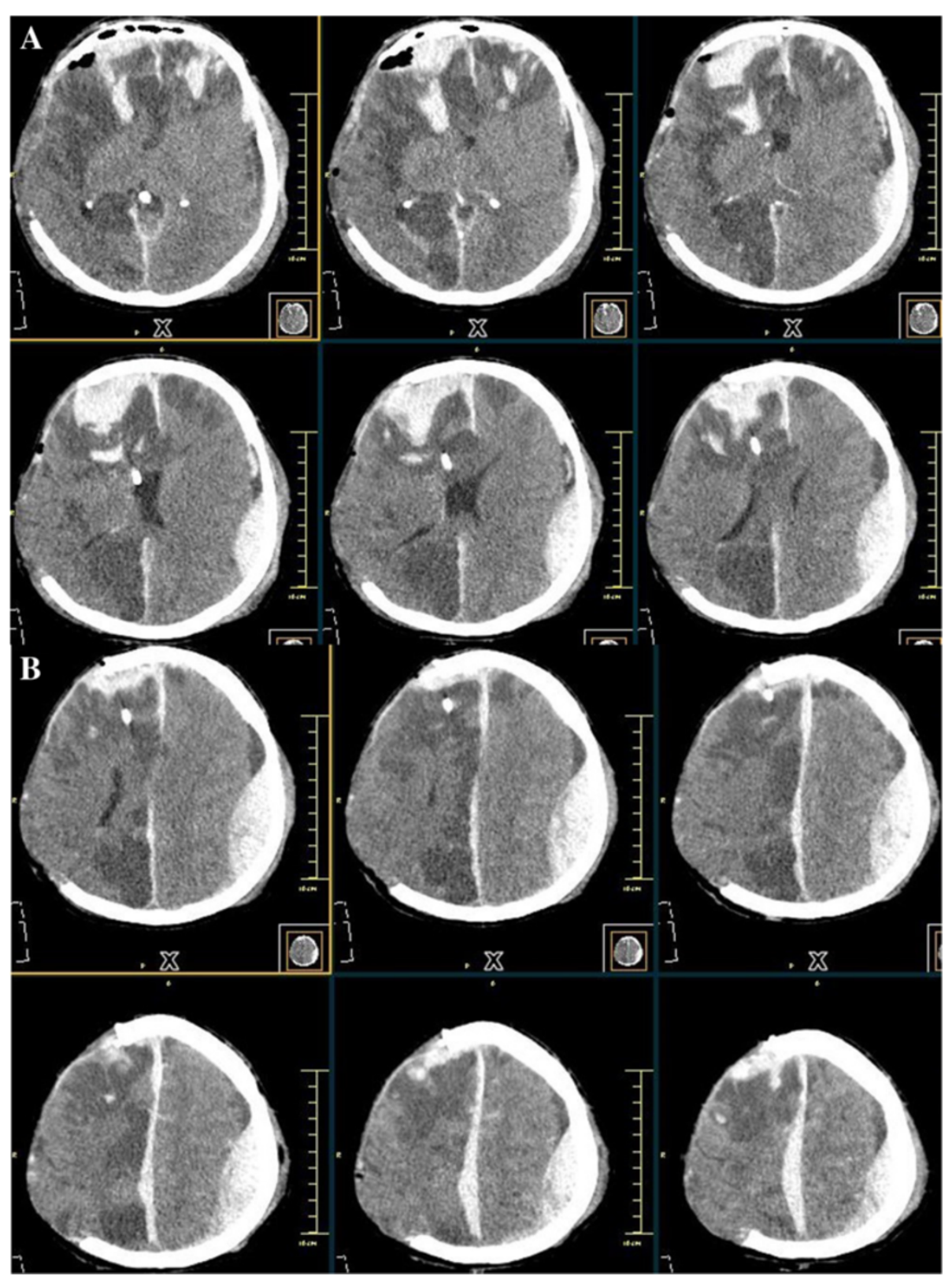

Figure 2 (A/B): Computed tomography following decompressive surgery showing contralateral extradural hematoma.

situation with only 38 cases previously reported in the English medical literature [6-10].

Several neurosurgical procedures have been reported to be associated with contralateral EDH, such as ventriculoperitoneal shunt insertion and evacuation of acute and chronic ASDH [6-10,14,15]. Shen et al. [6], in 2013, estimated that the percentage of occurrence of EDH contralateral to the site of drainage of ASDH was 2.4\% according to the published data. Most of the patients were male, with an average age of 35 years and with a main mechanism of traffic accident [6]. The present report describes the case of an adult who had a motorcycle accident who was admitted to our Emergency Room showing signs of severe neurological damage, with GCS of six points and anisocoria.

Many signs have been proposed as alert hints to the detection of contralateral EDH following drainage of ipsilateral ASDH, such as intra-operative brain swelling, postoperative neurological deterioration, pupillary dilation contralateral to the site of ASDH, grand mal seizure and intractable elevated ICP $[8,14,15]$. In our case, the patient was admitted in poor neurological status and was continuously sedated. ICP monitoring revealed increased ICP from the first postoperative day and was 


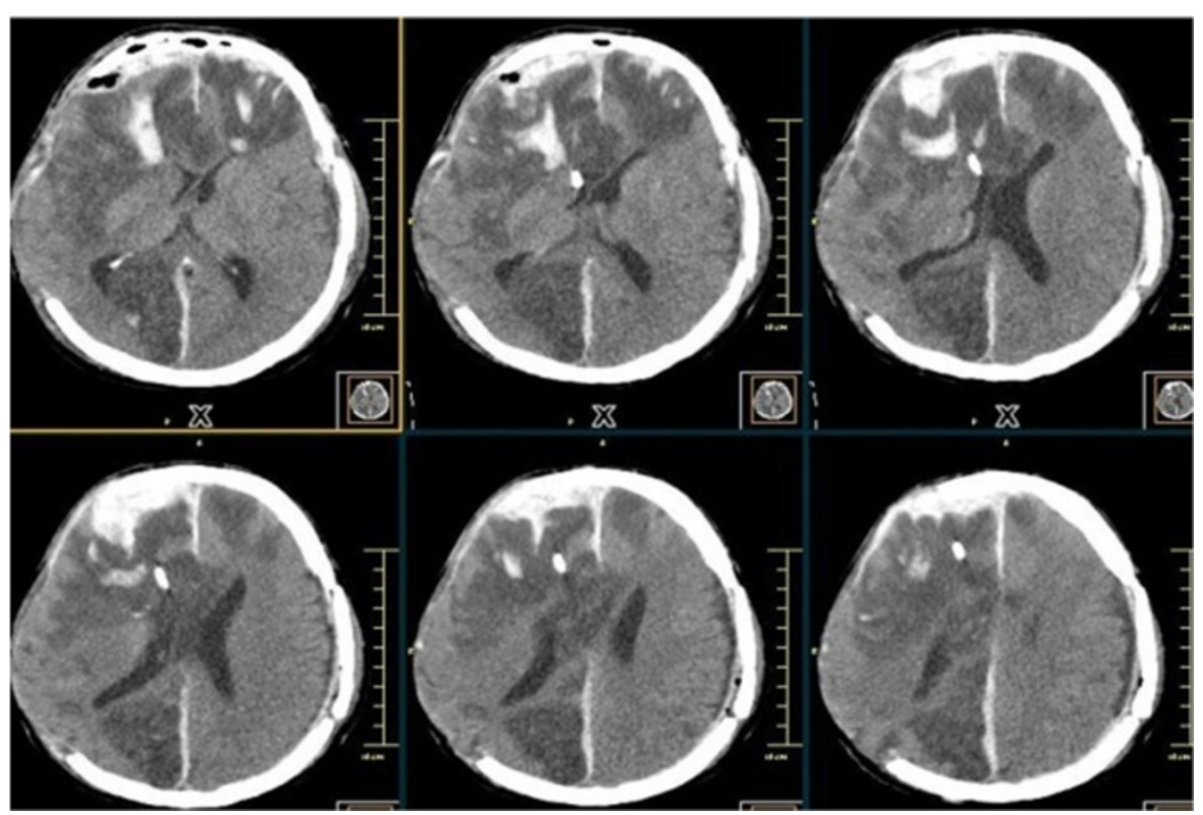

Figure 3 Computed tomography following drainage of extradural hematoma.

refractory to all initial clinical maneuvers. A postoperative CT showed the presence of a large contralateral $\mathrm{EDH}$. As already highlighted by other authors, on the presentation of "red flags" immediate CT is recommended because it may lead to urgent evacuation surgery of these life-threatening mass lesions $[7,16]$.

The pathophysiology involved in the formation of delayed contralateral EDH following decompressive surgery is not fully understood, but may include loss of tamponade effect, vasomotor mechanisms, and coagulopathy, with the main cause appearing to be the upsetting of the equilibrium of the damaged vessels and the reactive ICP [17]. In the present case, although a linear fracture ipsilateral to the ASDH had been identified on the admission CT, no other structural abnormality was found during drainage of contralateral EDH, making us believe that the main mechanism involved in our case was the loss of tamponade effect following decompressive surgery and microvascular ruptures in the virtual epidural space.

\section{Conclusions}

In conclusion, the present case highlights the importance of close monitoring of the ICP of patients who have severe TBI, even after decompressive procedures, because of the possible development of contralateral EDH. Although most instances of increased ICP after ASDH drainage seem to be associated with brain swelling, these phenomena should raise the suspicion of evolution of contralateral hematoma.

\section{Consent}

Written informed consent was obtained from the patient's next of kin for publication of this case report and any accompanying images. A copy of the written consent is available for review by the Editor-in-Chief of this journal.

\section{Competing interests}

The authors declare that they have no competing interests.

\section{Authors' contributions}

LCM, GBS, ECA, RE and FR participated on the surgeries of the patient. All authors helped to draft the manuscript. All authors read and approved the final manuscript.

\section{Author details}

'Faculdade de Medicina de São José do Rio Preto (FAMERP), Residente do Serviço de Neurocirurgia, Hospital de Base, São Paulo, Brazil. ${ }^{2}$ Faculdade de Medicina de São José do Rio Preto (FAMERP), Coordenador do Setor de Emergência do Serviço de Neurocirurgia, Hospital de Base, São Paulo, Brazil. ${ }^{3}$ Faculdade de Medicina de São José do Rio Preto (FAMERP), Chefe do Serviço de Neurocirurgia, Hospital de Base, São Paulo, Brazil. ${ }^{4}$ Rua Pedro Palotta, 101/31B. Jardim Maracanã, 15092205 São José do Rio Preto, São Paulo, Brazil.

Received: 9 November 2013 Accepted: 11 February 2014 Published: 16 May 2014

\section{References}

1. Centers for Disease Control and Prevention (CDC): CDC grand rounds: reducing severe traumatic brain injury in the United States. MMWR Morb Mortal Wkly Rep 2013, 62(27):549-552.

2. Udoh DO: Bilateral post-traumatic acute extradural hematomas: a report of four cases and review of literature. Niger J Clin Pract 2012, 15(1):104-107.

3. Le TH, Gean AD: Neuroimaging of traumatic brain injury. Mt Sinai J Med 2009, 76(2):145-162.

4. Zammit C, Knight WA: Severe traumatic brain injury in adults. Emerg Med Pract 2013, 15(3):1-28. Epub 2013 Feb 20. 
5. Gabrielian L, Helps SC, Thornton E, Turner RJ, Leonard AV, Vink R: Substance $P$ antagonists as a novel intervention for brain edema and raised intracranial pressure. Acta Neurochir Suppl 2013, 118:201-204.

6. Shen J, Pan JW, Fan ZX, Zhou YQ, Chen Z, Zhan RY: Surgery for contralateral acute epidural hematoma following acute subdural hematoma evacuation: five new cases and a short literature review. Acta Neurochir (Wien) 2013, 155(2):335-341.

7. Saberi H, Meybodi AT, Meybodi KT, Habibi Z, Mirsadeghi SM: Delayed postoperative contralateral epidural hematoma in a patient with right-sided acute subdural hematoma: a case report. Cases J 2009, 2:6282.

8. Su TM, Lee TH, Chen WF, Lee TC, Cheng CH: Contralateral acute epidural hematoma after decompressive surgery of acute subdural hematoma: clinical features and outcome. J Trauma 2008, 65(6):1298-1302.

9. Mohindra S, Mukherjee KK, Gupta R, Chhabra R, Gupta SK, Khosla VK: Decompressive surgery for acute subdural haematoma leading to contralateral extradural haematoma: a report of two cases and review of literature. Br J Neurosurg 2005, 19(6):490-494.

10. Boviatsis EJ, Korfias S, Kouyialis AT, Sakas DE: Epidural haematoma after evacuation of contralateral subdural haematoma. Ir J Med Sci 2004 173(4):217-218.

11. Massaro F, Lanotte M, Faccani G, Triolo C: One hundred and twenty-seven cases of acute subdural haematoma operated on. Correlation between CT scan findings and outcome. Acta Neurochir (Wien) 1996, 138(2):185-191.

12. Servadei F, Nasi MT, Giuliani G, Cremonini AM, Cenni P, Zappi D, Taylor GS: $C T$ prognostic factors in acute subdural haematomas: the value of the 'worst' CT scan. Br J Neurosurg 2000, 14(2):110-116.

13. Cordobés F, Lobato RD, Rivas JJ, Muñoz MJ, Chillón D, Portillo JM, Lamas E: Observations on 82 patients with extradural hematoma. Comparison of results before and after the advent of computerized tomography. $J$ Neurosurg 1981, 54(2):179-186

14. Power D, Ali-Khan F, Drage M: Contralateral extradural haematoma after insertion of a programmable-valve ventriculoperitoneal shunt. $J R$ Soc Med 1999, 92(7):360-361.

15. Panourias IG, Skandalakis PN: Contralateral acute epidural haematoma following evacuation of a chronic subdural haematoma with burr-hole craniostomy and continuous closed system drainage: a rare complication. Clin Neurol Neurosurg 2006, 108(4):396-399.

16. Matsuno A, Katayama H, Wada H, Morikawa K, Tanaka K, Tanaka H Murakami M, Fuke N, Nagashima T: Significance of consecutive bilateral surgeries for patients with acute subdural hematoma who develop contralateral acute epi- or subdural hematoma. Surg Neurol 2003, 60(1):23-30.

17. Lesoin F, Viaud C, Pruvo J, Redford H, Jomin M: Traumatic and alternating delayed intracranial hematomas. Neuroradiology 1984, 26:515-516.

\section{doi:10.1186/1752-1947-8-153}

Cite this article as: Meguins et al.: Contralateral extradural hematoma following decompressive craniectomy for acute subdural hematoma (the value of intracranial pressure monitoring): a case report. Journal of Medical Case Reports 2014 8:153.

\section{Submit your next manuscript to BioMed Central and take full advantage of:}

- Convenient online submission

- Thorough peer review

- No space constraints or color figure charges

- Immediate publication on acceptance

- Inclusion in PubMed, CAS, Scopus and Google Scholar

- Research which is freely available for redistribution

Submit your manuscript at www.biomedcentral.com/submit
Ciomed Central 